\title{
Prevention of Postoperative Deep Vein Thrombosis in Patients with Malignant Disease
}

\author{
V. C. ROBERTS, L. T. COTTON
}

British Medical fournal, 1974, 1, 358-360

\section{Summary}

We have used the ${ }^{125}$ I-fibrinogen test to assses the value of an improved method of peroperative intermittent calf compression as a prophylactic measure against postoperative thrombosis. In a group of 99 patients over the age of 40 undergoing operations lasting more than 30 minutes the technique reduced the incidence of postoperative thrombosis by over $75 \%$. In patients suffering from malignant disease, who are generally considered to be in the very high risk category, the reduction achieved was almost $90 \%$.

\section{Introduction}

In looking for a successful prophylactic measure against deep vein thrombosis we have concentrated on the stasis theory first proposed by Virchow (1856). Venous blood flow is greatly slowed during operation (Clark and Cotton, 1968) and our techniques have been developed to reduce or eliminate this

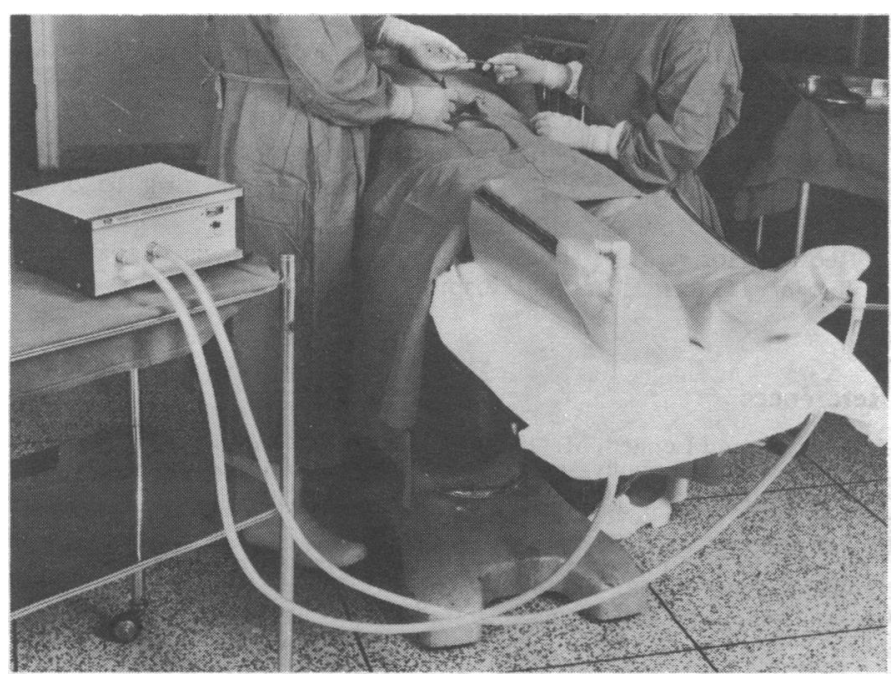

FIG. 1-The BOC-Roberts Venous Flow Stimulator in use during an operation.

venous stasis. Among the techniques which successfully reduce the incidence of postoperative thrombosis, as assessed by the radioactive fibrinogen test, are electrical calf stimulation (Browse and Negus, 1970; Nicholaides et al., 1972), passive flexion of the foot (Sabri et al., 1971 a), and intermittent compression of the calf (Sabri et al., 1971 b; Hills et al., 1972). The last of these, which has been studied in greatest detail haemo-

Department of Biomedical Engineering, King's College Hospital Medical School, London S.E.5

V. C. ROBERTS, PH.D., M.I.E.E., Lecturer

L. T. COTTON, M.CH., F.R.C.s., Consultant Surgeon and Director of Department dynamically (Roberts et al., 1972; Roberts and Cotton, 1972), seems to be the simplest of all prophylactic techniques. In our first trial of it (Sabri et al., 1971 b) each patient acted as his own control by having only one leg treated. It showed that intermittent compression of the leg during operation could reduce the incidence of postoperative thrombosis in the first six postoperative days by $82 \%$.

Other workers have also found intermittent compression effective (Hills et al., 1972), but only by covering the whole of the period from preoperative medication to postoperative ambulation. Furthermore, this was completely ineffective when applied to patients with malignant disease. Our original trial of intermittent compression had suggested that our method was able to prevent deep vein thrombosis in patients with malignant disease, but the numbers were too small to be statistically significant. We therefore began another trial. We had succeeded in developing a much-improved device for squeezing the legs (Roberts et al., 1973), the BOC-Roberts Venous Flow Stimulator (fig. 1), and it was used on all patients in this further trial, the results of which we report in this paper.

\section{Patients and Methods}

Patients of both sexes over the age of 40 who were undergoing surgical operation lasting more than 30 minutes were asked for their co-operation and written consent. Those who had a previous history of thrombosis or who were having leg, thyroid, or vascular surgery were excluded. All others were entered consecutively in the trial and assigned randomly to either the treatment or non-treatment group by selection of a card from a pack. In this way a reasonable numerical balance between the groups was assured for a fairly small group of patients. All patients were monitored for radioisotopic evidence of postoperative deep vein thrombosis. The thyroid was blocked with $100 \mathrm{mg}$ of sodium iodide given orally 24 hours before injection of ${ }^{125} \mathrm{I}$ fibrinogen and continued daily for 28 days. An injection of $100 \mu \mathrm{Ci}$ of ${ }^{125} \mathrm{I}$ fibrinogen (Radiochemical Centre, Amersham) was given into an arm vein and the radioactivity measured over the legs 30 minutes later.

The counting equipment used was the Pitman 235 isotope monitor and the legs were scanned according to the modified method of Flanc et al. (1968) in which counts are expressed as a percentage of the precordial count. The legs were scanned two hours before the operation, 10 minutes after it, and daily for the first three postoperative days. A further scan was made on the sixth postoperative day. If there was a raised count on day three scans were also made on days four and five. The diagnosis of venous thrombosis was made when the postoperative count of radioactivity at any site differed by $20 \%$ or more from either the preoperative value, an adjacent measurement point on the same leg, or the same point on the other leg. The diagnosis of thrombosis was confirmed when this difference persisted for more than 24 hours.

The treated group of patients had the intermittent compression device applied to their legs while they were on the operating table. The legs were placed in special plastic splints (below-knee type) which were coupled to a pneumatic regulator connected to a source of compressed air. The device delivered short, sixsecond compressions with a maximum pressure of $45 \mathrm{~mm} \mathrm{Hg}$ to each leg every 100 seconds. The machine was completely preset and needed no adjustments. 


\section{Results}

This trial is continuing and the present results are from the first 102 patients. Three were removed from the trial-in one case because the patient was given an epidural anaesthetic postoperatively, in another because the patient's legs were bandaged, and in a third because the machine failed halfway through the operation. Of the remaining 99 patients 47 were treated by peroperative calf compression and 52 were untreated (table).

Details of Treated and Untreated Groups

\begin{tabular}{|c|c|c|c|c|c|c|}
\hline & \multirow{2}{*}{$\begin{array}{c}\text { Average } \\
\text { Age }\end{array}$} & \multicolumn{2}{|c|}{ Sex } & \multirow{2}{*}{$\begin{array}{l}\text { Average } \\
\text { Duration of } \\
\text { Operation } \\
\text { (min) }\end{array}$} & \multirow{2}{*}{$\begin{array}{c}\text { No. with } \\
\text { Malignant } \\
\text { Disease }\end{array}$} & \multirow{2}{*}{$\begin{array}{c}\text { No. without } \\
\text { Malignant } \\
\text { Disease }\end{array}$} \\
\hline & & M. & F. & & & \\
\hline Treated .. & $60 \cdot 5 \pm 9 \cdot 1$ & 21 & 26 & $89.4 \pm 42.9$ & 23 & 24 \\
\hline Untreated & $60 \cdot 3 \pm 9 \cdot 7$ & 25 & 27 & $98.5 \pm 39.0$ & 20 & 32 \\
\hline
\end{tabular}

The effectiveness of the prophylaxis was assessed by the number of thromboses detected over the six-day period. In the 104 untreated limbs 27 thrombi were detected, while in the 94 treated limbs only six were detected-an incidence of $26.0 \%$ and $6.4 \%$ respectively and a relative reduction of $75.4 \%$. When assessed by the $\chi^{2}$ test after applying Yates's correction this result is highly significant. It is also interesting that all the thromboses in the treated group were unilateral, whereas in the untreated group one half of the thromboses were unilateral and one half bilateral.

The results in patients with malignant disease were stratified according to age. In the control group the incidence of thrombosis in the lower age group (40-59) was $33.3 \%$ while in the higher age group $(\geqslant 60)$ it was $32 \cdot 1 \%$. In the treated group the incidence in 30 treated limbs in the older age group was one $(3.3 \%)$ and in 16 treated limbs in the younger group it was also only one $(6 \cdot 2 \%)$-a reduction of $89.7 \%$ and $81 \cdot 4 \%$ respectively. Applying Yates's correction and the $\chi^{2}$ test yields a significance level of $P<0.005$ and $P<0.02$ for the older and younger groups respectively, which is highly significant in both cases.

Prophylactic regimens applied only during the operative period have been said to be effective mainly by delaying the onset of thrombosis. We therefore analysed the incidence of thrombosis in the treated and untreated groups of patients according to the postoperative day on which the thrombosis occurred. The result (fig. 2) shows the dramatic effect of our prophylactic regimen. Clearly the onset of thrombosis is not delayed by intermittent compression during operation, unless it is until after the sixth postoperative day. Notably $80 \%$ of the thrombi have appeared by the third day in the treated group while $72 \%$ have appeared in the untreated group.

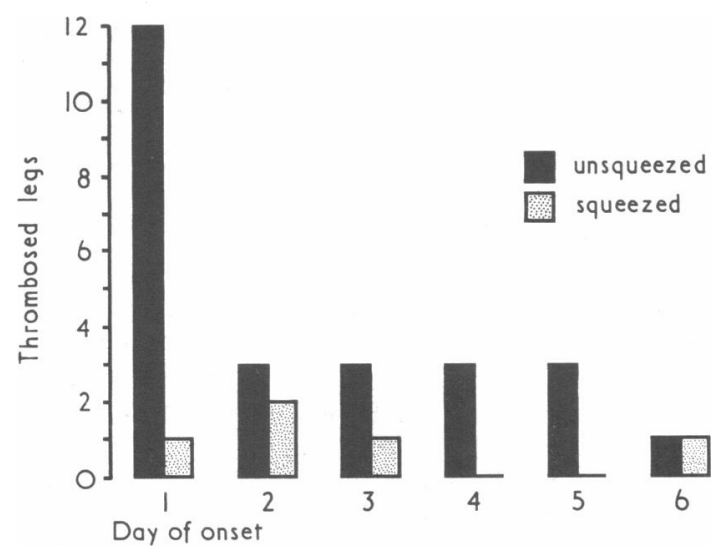

FIG. 2-Analysis of day of onset of deep vein thrombosis for untreated and treated groups of patients.
We were also interested to see whether the pattern of onset of thrombosis in patients with malignant disease differed from the normal (fig. 3). The analysis is of cases of thrombosis among the untreated group of patients. As can be seen, the distribution of thrombosis according to the day of onset is very different in the two groups of patients. Thrombosis had occurred in $69 \%$ of patients with malignant disease by the first postoperative day compared with $21 \%$ in patients without malignant disease. In the non-malignant group the time of onset of thrombosis is spread fairly evenly over the six postoperative days. Since the duration and severity of the operations in each group of patients might have had a bearing on this difference we analysed the incidence of thrombosis in the two groups in relation to the duration of the operation performed. The mean duration of operation in patients with malignant disease who developed thrombosis was 117 minutes (S.D. $\pm 27 \cdot 4$ ) and in patients without malignant disease it was 107 minutes (S.D. $\pm 29 \cdot 9$ ). The difference is not significant. The mean duration of operation in patients with malignant disease who did not develop thrombosis was 92.3 minutes (S.D. $\pm 44 \cdot 4$ ) while in those without malignant disease it was $86 \cdot 3$ minutes (S.D. $\pm 46 \cdot 5$ ). The difference is again not significant.

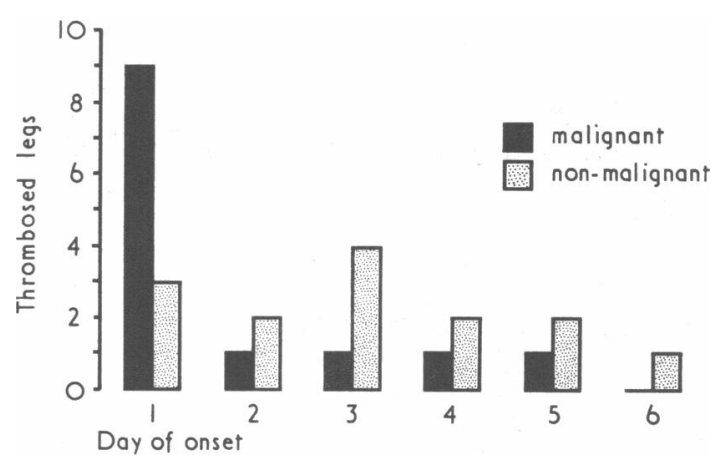

FIG. 3-Analysis of day of onset of deep vein thrombosis for untreated patients with and without evidence of malignant disease.

\section{Discussion}

Our technique for preventing postoperative deep vein thrombosis had an overall success rate of more than $75 \%$ as judged by the ${ }^{125} \mathrm{I}$-fibrinogen test over the first six postoperative days. Moreover, we reduced the incidence of postoperative thrombosis in patients with malignant disease by almost $90 \%$. We have also shown that patients with malignant disease are more likely to develop thrombosis early during the postoperative period. This does not seem to have been because of the slightly longer operations these patients underwent, and the explanation may lie in the studies of Miller et al. (1967), which led them to suggest that the natural haemostatic balance was set at a higher level in patients with malignant disease and consequently was much more readily upset by stimuli such as tissue trauma. When there is also haemodynamic insufficiency during operation the balance is even more critical and could explain the immediate postoperative onset of thrombosis in so many of these patients. Nevertheless, at present this can be no more than hypothesis.

This apparently different pattern of thrombosis in patients with malignant disease may also explain why our method of prophylaxis was more successful in that group. In our technique intermittent compression of the calf is applied only while the patient is on the operating table and has been carefully designed to produce the maximum disturbance to the venous flow patterns in the leg (Roberts and Cotton, 1972). Thus we are most effectively combatting the effects of stasis during the operative period. The other workers in this field (Hill et al., 1972) have been unable to affect the incidence of thrombosis in patients with malignant disease. We have analysed the haemodynamic effects of their device (Roberts and Cotton, 1972) and have 
shown it to be far less effective in producing a disturbance in the venous flow. This may well explain their lack of success in preventing thrombosis in patients with malignant disease.

\section{Conclusion}

We have shown that our technique of peroperative intermittent calf compression, which produces the maximum haemodynamic disturbance in the leg veins, can reduce the incidence of postoperative thrombosis by more than $75 \%$ in patients aged over 40. More important, however, is the finding that in patients with malignant disease, hitherto regarded as "very high risk," the incidence can be reduced by almost $90 \%$. We believe our technique to be the best currently available for preventing postoperative thrombosis.

We would particularly thank Mrs. D. Berlyn for technical and secretarial help and Mrs. A. Young for technical help. We would also thank the British Heart Foundation and the Wates Foundation for their generosity in financing this investigation, the British Oxygen Company for providing the Venous Flow Stimulators, and Mr. H. E. Berry and Mr. E. Howard for allowing us access to their patients.

\section{References}

Browse, N. L., and Negus, D. (1970). British Medical fournal, 3, 615.

Clark, C., and Cotton, L. T. (1968). British fournal of Surgery, 55, 211

Flanc, D., Kakkar, V. V., and Clarke, M. B. (1968). British fournal of Surgery, 55, 742 .

Hills, N. H., Pflug, J. J., Jeyasingh, K., Boardman, L., and Calnan, J. S. (1972). British Medical fournal, $1,131$.

Miller, S. P., Sanchez-Avalos, J., Stefanski, T., and Zucherman, L. (1967). Cancer (Philadelphia), 20, 1452.

Nicholaides, A. N., Kakkar, V. V., Field, E. S., and Fish, P. (1972). In Thromboembolism, ed. V. V. Kakkar and A. J. Jouhar. Edinburgh, Churchill Livingstone.

Roberts, V. C., and Cotton, L. T. (1972). In Blood Flow Measurement, ed. V. C. Roberts. London, Sector Publishing.

Roberts, V. C., Cotton, L. T., Derry, C., and McGrath, J. A. (1973). Proceedings of the Tenth International Conference on Medical and Biological Engineering, 19-8.

Roberts, V. C., Sabri, S., Beeley, A. H., and Cotton, L. T. (1972). British fournal of Surgery, 59, 223.

Sabri, S., Roberts, V. C., and Cotton, L. T. (1971 a). British Medical , S., Roberts,

Sabri, S., Roberts, V. C., and Cotton, L. T. (1971 b). British Medical fournal, 4, 394.

Virchow, R. L. K. (1856). Thrombose and Embolie. Frankfurt.

\title{
T and B Lymphocytes: Striking Differences in Surface Membranes
}

\author{
J. N. MEHRISHI, K. ZEILLER
}

British Medical fournal, 1974, 1, 360-362

\section{Summary}

Lymphocytes can be separated by electrophoresis into cells of high and of low electrophoretic mobility. Cells of high mobility are $\mathbf{T}$ cells and those of low mobility are $\mathbf{B}$ cells, with distinct immunological functions. Biophysical and biochemical studies on physically isolated and immunologically defined $T$ and $B$ cells in CBA mice showed striking differences in the chemical composition of the surface membranes.

\section{Introduction}

Cells of lymphoid origin can be separated on the basis of the net surface charge (negative) by free-flow electrophoresis (Hannig and Zeiller, 1969) into two distinct subpopulations of high and low electrophoretic mobilities without loss of viability and with very lintle overlap (Hannig and Zeiller, 1969; Zeiller et al., 1972; Nordling et al., 1972; Seiler et al., 1974). Routine immunological methods show that the lymphocytes in the high mobility region are $T$ cells whereas the cells in the low mobility region are B cells (Zeiller et al., 1972; Nordling et al., 1972; Seiler, et al., 1974).

S.tudies (Mehrishi, 1972 a; Mehrishi, 1972 b) on normal human lymphocytes (isolated from the peripheral blood by a method such as the carbonyl iron-methyl cellulose method

Max-Planck Institut fur Biochemie, 8033 Martinsried, bei Munchen J. N. MEHRISHI, PH.D., F.R.I.C. (Present address: Department of Radiotherapeutics, University of Cambridge, Hills Road, Cambridge CB2 2QH) K. ZEILLER, M.D.
(Coulson and Chalmers, 1964) but not separated funther into subpopulations) showed the presence of positively charged groups and sulphydryl groups and at least three types of negatively charged groups in the cell periphery.

Isolation of mouse $\mathrm{T}$ and $\mathrm{B}$ lymphocytes into high mobility regions and low mobility regions raised the obvious question: is the characteristic distribution of the electrophoretic mobilities of $T$ and $B$ cells, which perform distinot immunological functions, due to some striking differences in the chemical composition of their surface membranes? The different structures in the periphery of these cells probably give them their specific surface propenties and govern the reactions taking place at the cell surface. Information on the surface chemistry of $T$ and $B$ cells would help us to understand the mechanisms of cellular interactions in molecular terms and would clearly be of much interest in immunobiological research.

We describe here the results of a study of the surface topochemistry of physically and functionally defined $T$ and $B$ cells. The study showed striking differences in the chemical composition of the peripheral regions (within $8 \AA$ from the surface) of $T$ and $B$ cells in CBA mice.

\section{Methods}

Lymph nodes, spleen, and thymus from several adult spf/ $\mathrm{CBA} / \mathrm{J}$ mice were removed, separately pooled, and the respective cell suspensions prepared for preparative free-flow electrophoresis (Hannig and Zeiller, 1969). The electrophoretic separation of the cells was carried out in a low ionic strength buffer at $6^{\circ} \mathrm{C}(210 \mathrm{~mA} 100 \mathrm{~V} / \mathrm{cm})$, using a refined model of the electrophoretic separator FF4 (Desaga, Heidelberg; Bender and Hobein, Munich) (Hannig and Zeiller, 1969). Cell fraotions from the shaded portion of the curves shown in the graph contained homogeneous 